\title{
Molecular characterization of the dominant-negative role of cancer-associated PTEN: sometimes, null is better
}

\section{Saverio Marchi and Paolo Pinton*}

Laboratory for Technologies of Advanced Therapies (LTTA), Section of Pathology, Oncology and Experimental Biology, Department of Morphology, Surgery and Experimental Medicine, University of Ferrara, Ferrara, Italy

${ }^{*}$ Correspondence: pnp@unife.it

Edited by:

Hans-Uwe Simon, University of Bern, Switzerland

Reviewed by:

Robert Friis, University of Bern, Switzerland

\section{A commentary on}

Cancer-associated PTEN mutants act in a dominant-negative manner to suppress PTEN protein function

by Papa A, Wan L, Bonora M, Salmena L, Sup Song M, Hobbs RM, et al. Cell (2014)

157: 595-610. doi:10.1016/j.cell.2014.03. 027

A number of observations have radically expanded our knowledge regarding the signaling pathways that regulate the tumor suppressor PTEN. These findings are derived from the molecular characterization of cancer-associated dominantnegative PTEN mutants, as well as the identification of alternative forms and intracellular localizations of PTEN.

The lipid and protein phosphatase PTEN (Phosphatase and tensin homolog located on chromosome 10) is one of the most common tumor suppressors that is lost or mutated in several human cancers. Different mechanisms contribute to PTEN loss of function, which include post-translational modifications, interaction with other proteins, missense and truncation mutations, as well as gene deletions. The role of PTEN as an oncosuppressor has mainly been characterized through the study of different PTEN-null tumor cell lines or transgenic mice engineered to carry one wild-type (WT) copy and one null allele of PTEN $\left(\right.$ PTEN $\left.^{+/-}\right)$. However, a paper published in 1998 by the group of Eng and co-workers reported that PTEN loss-of-function mutations might not contribute to tumorigenesis to the same extent as the genetic loss of PTEN. This study was conducted on patients affected by Cowden disease, a PTEN hamartoma tumor syndrome, and revealed that patients with missense PTEN mutations in the phosphatase domain developed higher numbers of lesions compared to patients with truncating mutations (1). The mechanistic and molecular role of PTEN mutations in cancer has been recently defined in a paper published in Cell (2). Papa et al. showed that different PTEN mutants, previously identified in tumors (i.e., PTEN C124S, PTEN G129E, and PTEN R130G), form heterodimeric structures with the WT enzyme, thereby inhibiting PTEN activity in a dominant-negative manner and leading to aberrant Akt activation (2). Moreover, it has been observed that dephosphorylation of the PTEN tail not only promotes an open conformation of the enzyme but also favors the formation of dimers or oligomers (2). The heterozygous expression of cancer-associated PTEN mutations allows the generation of catalytically inactive heterodimers. Consequently, increased PIP3 levels induce Akt hyperactivation and augment tumor progression. Thus, a neoplasm characterized by PTEN mutations is more unfavorable than a PTEN-null cancer context. Interestingly, this now reveals that the malignant activity of mutant PTENs is analogous to that of mutant p53: p53, a tumor suppressor also frequently mutated in cancers, normally functions in a tetrameric conformation; moreover, p53 mutants can similarly act as dominant-negative inhibitors of residual WT protein (3).

The ability of mutant PTEN to heterodimerize and inhibit the WT enzymatic activity is one of the recent findings that have radically expanded our knowledge on PTEN activity and functions. Firstly, the identification of an alternative variant of PTEN, named PTEN-Long, containing an extra 173 aminoacidic domain at its $\mathrm{N}$-terminus, followed by the canonical PTEN sequence (4). The resulting 576aminoacids protein is less abundant than the short isoform; it has been founded to be mutated in tumor samples and can be secreted to enter other cells $(4,5)$.

Furthermore, it has been shown as PTEN $\alpha$, a 70-kDa PTEN variant that most likely corresponds to PTEN-Long (5), controls mitochondrial metabolism and the energy status of the cell (6). PTEN $\alpha$ can interact with canonical PTEN, forming heterodimers that regulate mitochondrial bioenergetics (6). Interestingly, transgenic mouse lines with PTEN expression displayed increased mitochondrial oxidative phosphorylation and ATP production (7). Unlike canonical PTEN, which plays a well-defined role in signaling at the plasma membrane and nucleus, PTEN $\alpha$ localizes mainly to the cytosol and mitochondria (6). In line with this, alternative subcellular localizations of PTEN, such as to the nucleoli (8) and mitochondriaassociated endoplasmic reticulum membranes (MAM) (9), have been recently described. Our group demonstrated that PTEN interacts with the inositol-1,4,5trisphosphate receptor (IP3R) at endoplasmic reticulum (ER) to counteract Akt activity, consequently favoring calcium $\left(\mathrm{Ca}^{2+}\right)$ transfer into the mitochondria and the initiation of apoptosis (9, 10). Accordingly, we and other labs proposed that Akt kinase might potentiate its anti-apoptotic activity through IP3R phosphorylation and the reduction of $\mathrm{Ca}^{2+}$ release from the ER (11-14). Thus, PTEN acts at multiple subcellular levels, regulating PI3K signaling through its phosphatase activity.

Although the ER-targeted C124S and G129E PTEN chimeras still maintain their 
ability to suppress Akt activation (9), there is currently no evidence that cancerassociated PTEN mutants operate at specific subcellular compartments. Nevertheless, upon starvation/serum stimulation, C124S and G129E mutants translocate more rapidly to the plasma membrane than the WT form (2).

The very recent characterization of a bioluminescence resonance energy transfer (BRET)-based biosensor, which is capable of detecting signal-dependent PTEN conformational changes in live cells (15), may represent a valuable tool for elucidating PTEN activity and functions.

\section{ACKNOWLEDGMENTS}

The Italian Association for Cancer Research (AIRC) Telethon (GGP11139B), the Italian Ministry of Health, the Italian Ministry of Education, University and Research (COFIN, FIRB, and Futuro in Ricerca), and local funds from the University of Ferrara to Paolo Pinton.

\section{REFERENCES}

1. Marsh DJ, Coulon V, Lunetta KL, Rocca-Serra P, Dahia PL, Zheng Z, et al. Mutation spectrum and genotype-phenotype analyses in Cowden disease and Bannayan-Zonana syndrome, two hamartoma syndromes with germline PTEN mutation. Hum Mol Genet (1998) 7:507-15. doi:10.1093/ hmg/7.3.507

2. Papa A, Wan L, Bonora M, Salmena L, Song MS Hobbs RM, et al. Cancer-associated PTEN mutants act in a dominant-negative manner to suppress PTEN protein function. Cell (2014) 157:595-610. doi:10.1016/j.cell.2014.03.027
3. Leslie NR, den Hertog J. Mutant PTEN in cancer: worse than nothing. Cell (2014) 157:527-9. doi:10.1016/j.cell.2014.04.008

4. Hopkins BD, Fine B, Steinbach N, Dendy M, Rapp $Z$, Shaw J, et al. A secreted PTEN phosphatase that enters cells to alter signaling and survival. Science (2013) 341:399-402. doi:10.1126/science.1234907

5. Pulido R, Baker SJ, Barata JT, Carracedo A, Cid VJ, Chin-Sang ID, et al. A unified nomenclature and amino acid numbering for human PTEN. Sci Signal (2014) 7:e15. doi:10.1126/scisignal.2005560

6. Liang $\mathrm{H}$, He S, Yang J, Jia X, Wang $\mathrm{P}$, Chen $\mathrm{X}$, et al. PTENalpha, a PTEN isoform translated through alternative initiation, regulates mitochondrial function and energy metabolism. Cell Metab (2014) 19:836-48. doi:10.1016/j.cmet.2014.03.023

7. Garcia-Cao I, Song MS, Hobbs RM, Laurent G, Giorgi C, De Boer VC, et al. Systemic elevation of PTEN induces a tumor-suppressive metabolic state. Cell (2012) 149:49-62. doi:10.1016/j.cell. 2012.02.030

8. Li P, Wang D, Li H, Yu Z, Chen X, Fang J. Identification of nucleolus-localized PTEN and its function in regulating ribosome biogenesis. Mol Biol Rep (2014). doi:10.1007/s11033-014-3518-6

9. Bononi A, Bonora M, Marchi S, Missiroli S, Poletti F, Giorgi C, et al. Identification of PTEN at the ER and MAMs and its regulation of $\mathrm{Ca}(2+)$ signaling and apoptosis in a protein phosphatase-dependent manner. Cell Death Differ (2013) 20:1631-43. doi: 10.1038/cdd.2013.77

10. Bonora M, Bononi A, De Marchi E, Giorgi C, Lebiedzinska M, Marchi S, et al. Role of the c subunit of the FO ATP synthase in mitochondrial permeability transition. Cell Cycle (2013) 12:674-83. doi:10.4161/cc.23599

11. Szado T, Vanderheyden V, Parys JB, De Smedt H, Rietdorf K, Kotelevets L, et al. Phosphorylation of inositol 1,4,5-trisphosphate receptors by protein kinase B/Akt inhibits $\mathrm{Ca} 2+$ release and apoptosis. Proc Natl Acad Sci U S A (2008) 105:2427-32. doi:10.1073/pnas.0711324105

12. Giorgi C, Ito K, Lin HK, Santangelo C, Wieckowski MR, Lebiedzinska $\mathrm{M}$, et al. PML regulates apoptosis at endoplasmic reticulum by modulating calcium release. Science (2010) 330:1247-51. doi:10.1126/science.1189157

13. Marchi S, Marinello M, Bononi A, Bonora $\mathrm{M}$, Giorgi C, Rimessi A, et al. Selective modulation of subtype III IP(3)R by Akt regulates ER Ca(2)(+) release and apoptosis. Cell Death Dis (2012) 3:e304. doi:10.1038/cddis.2012.45

14. Betz C, Stracka D, Prescianotto-Baschong C, Frieden M, Demaurex N, Hall MN. Feature article: mTOR complex 2-Akt signaling at mitochondriaassociated endoplasmic reticulum membranes (MAM) regulates mitochondrial physiology. Proc Natl Acad Sci U S A (2013) 110:12526-34. doi:10. 1073/pnas. 1302455110

15. Lima-Fernandes E, Misticone S, Boularan C, Paradis JS, Enslen H, Roux PP, et al. A biosensor to monitor dynamic regulation and function of tumour suppressor PTEN in living cells. Nat Commun (2014) 5:4431. doi:10.1038/ncomms5431

Conflict of Interest Statement: The authors declare that the research was conducted in the absence of any commercial or financial relationships that could be construed as a potential conflict of interest.

Received: 31 July 2014; accepted: 22 September 2014; published online: 10 October 2014.

Citation: Marchi S and Pinton P (2014) Molecular characterization of the dominant-negative role of cancerassociated PTEN: sometimes, null is better. Front. Oncol. 4:276. doi: 10.3389/fonc.2014.00276

This article was submitted to Molecular and Cellular Oncology, a section of the journal Frontiers in Oncology. Copyright (c) 2014 Marchi and Pinton. This is an openaccess article distributed under the terms of the Creative Commons Attribution License (CC BY). The use, distribution or reproduction in other forums is permitted, provided the original author(s) or licensor are credited and that the original publication in this journal is cited, in accordance with accepted academic practice. No use, distribution or reproduction is permitted which does not comply with these terms. 